\title{
The Influence of College Students' Self-Confidence and Strategies to Improve Self-Confidence
}

\author{
ShuJuan Zhao ${ }^{1 *}$, ShiQing $\mathrm{Wei}^{1}$, JunQian $\mathrm{Luo}^{2}$, MingRu $\mathrm{Li}^{3}$ \\ ${ }^{1}$ Jose Rizal University,0900, Education Management, Manila, Philippines \\ ${ }^{2}$ The First People's Hospital of JINZHONG, 030600, ShanXi, China \\ ${ }^{3}$ Urumqi No.126 Middle School, Urumqi, XinJiang, 830000, China \\ Email: zshj625@163.com
}

\begin{abstract}
College students are the main force for future social construction, and the mental health of college students is related to the development and progress of society. On the basis of consulting a large number of documents, the author discusses the impact of self-confidence on college students, the current situation of college students' self-confidence, and proposes how to improve college students' self-confidence.
\end{abstract}

Keywords: college students, self-confidence, mental health.

Self-confidence is an individual's affirmation of various aspects of himself, and is a stable character of objective, correct cognition and evaluation of one's own ability and value. Self-confident people can look up to themselves, believe in themselves, and dare to meet challenges and achieve success [1]. Self-confidence is the core component of individual personality, self-confidence is an important psychological mechanism for human adaptation to society [2]. It plays an important role in individual psychological activity and psychological development [3].

College students are an important force in social development and bear the important task of building the future of human society. The self-confidence level of college students is an important indicator of their mental health and is related to social development and progress. The university stage is an important period for the formation of individual personality and plays an important role in the development of individuals.

\section{The Effect of Self-Confidence on College Students}

\subsection{Self-Confidence Promotes the Physical and Mental Health of Students}

The study found that self-confidence is not only beneficial to mental health, but also an important indicator of the development of mental health. Individuals with high self-confidence levels have a high level of physical and mental health [4].

In addition to the difference between high and low levels of self-confidence, self-confidence also has characteristics of complexity, clarity and stability [5]. These cognitive structural characteristics have a buffering effect on mental illness, depression, anxiety, etc. [6, 7]. Some studies have found that the certainty of self-confidence components and internal harmony have a predictive effect on mental health [8].

\subsection{In Terms of Self-Regulation, Self-Confidence and Achievement Motivation Are Positively Correlated [9]}

Confidence plays an important role in students' learning. Research by psychologist Georgiou in 1999 showed that students with higher academic confidence proved to be high achievers. Intrinsic motivation is an important part of improving students' confidence in learning.

Dhall and Thukral (1987) used 1,000 students who study in 9th grade from four districts in Punjab, Pakistan as a sample to study the relationship between intelligence, self-confidence and academic 
performance. The study found that intelligence was positively correlated with self-confidence and academic performance.

Stevens' research in 2005 showed that confident children have high academic performance. Children who think they are worthless lack confidence and may not reach the best level of achievement. When students with low academic confidence enter university, they have lower academic skills, their participation is lower, and they face more difficulties in transition (Shoemaker, 2010; Sander \& Sanders, 2005).

In 2011, Farooq and others studied the influence of different factors on the academic confidence of grade 10 students (300 men and 300 women) in a large city in Pakistan. The survey results show that self-confidence has a positive effect on children's academic performance (House, 1997).

\subsection{Individuals with High Self-Confidence Level Have Less Interpersonal Trouble [10]}

Symbolic interaction theory believes that people's views on themselves are influenced by the views and attitudes of others, and individuals cannot form a complete self-evaluation without being separated from social processes. In the process of self-confidence formation, individuals form their own anchors through self-comparison and social comparison. Confidence changes caused by interpersonal evaluation help people make social decisions.

Roshani's research results show that among college students, there is a positive correlation between social support and social confidence. [11] Panzarella pointed out that there has always been an inverse relationship between social support and self-esteem. Ohet explored the relationship between social confidence, self-esteem and social support of college students and the self-efficacy of their interpersonal interactions, and found a positive correlation between social confidence and social support. Self-esteem and social confidence also have a significant relationship. Chiu found that social support has a significant effect on self-esteem. [12]

Zhang Jiyuan and Bi Chongzeng conducted a study of 315 college students in 2012 and found that self-confidence helps individuals reduce their interpersonal distress. The higher the level of self-confidence, the less interpersonal distress; the clarity of self-confidence plays a partial mediating effect between self-confidence and interpersonal distress. The intermediary effect accounts for $40.83 \%$ of the total effect [13].

Sun Bin, Ge Cao found that college students' social support and self-confidence were significantly positively correlated [14]. In 2018, studies by Wei YaoYang and Wang Yan showed that self-esteem has a predictive effect on social self-confidence, which can be enhanced by strengthening social support and self-esteem [15]. The answer will carry out research on the related research of college students' self-confidence, self-esteem, self-efficacy and mental health, and analysis will point out the relationship between college students' self-confidence and social support [16]. The results of these studies indicate that self-confidence helps individuals reduce the distress of social interaction.

\subsection{People with High Self-Confidence Level Have a Greater Chance of Success}

In 2006, Jonsson discussed the relationship between self-confidence and many variables such as violence, drug abuse, bullying, relationships, and academic achievement. Studies have also shown that people with strong self-confidence play an important role in academic achievement, social and personal responsibility (Naderi, Abdullah, Aizan, Sharir \& Kumar, 2009). Some psychologists have tracked and surveyed hundreds of teenagers with high levels of intellectual development, and roughly the same living environment and educational conditions. The results of the study show that individual psychological stereotypes play an important role in the process of success. Those who have a more stable self-affirmation tend to have a greater success rate than those with more self-denial. Self-confidence as a positive and internal motivation, its development level corresponds to the success or failure of the activity.

\section{The Status of College Students' Self-Confidence}

In 2009, research by Liu Wei et al. showed that a considerable proportion of college students have insufficient self-confidence, and the proportion is as high as 30-40\%, and even some students have a strong sense of inferiority [17]. At the same time, the Federation of Malaysian Employers (2009) stated that the 
problem faced by employers in hiring fresh graduates is a lack of self-confidence, especially in terms of rapport with the business community, especially soft skills in communication skills.

In 2011, Zhang Zhijun's survey of 240 college students showed that more than half of the self-confidence of college students was at the average level, accounting for $58.20 \%$; the number of people with self-confidence at strong and weak levels accounted for $19.90 \%$ and $21.90 \%$ respectively. The percentage of people in the strong level is slightly lower than that of the weak level [18].

In 2015, Zhu ChuanLin and Qi ZhengYang surveyed the self-confidence of college students and pointed out that many of them have low self-assessment. Many of them think that they can't do anything in front of what they can accomplish. Too strong self-seeking negative evaluation is commonly called inferiority complex. Students with inferiority complex are cowardly, relying on teachers, parents and classmates everywhere, and have low activity efficiency [19].

In 2016, Ms. Maheswari and K. Maheswari researchers used a descriptive research design and adopted a purposeful sampling method to select 60 boys. The main findings of the study indicate that more than half of the respondents $(52.5 \%)$ have low self-esteem, and $47.5 \%$ of them have high self-esteem [20].

The 2017 Gallup and Strada University Student Survey found that college students are experiencing a "confidence crisis" in their future careers. Here are some key findings from the study, which surveyed more than 32,000 college students in 43 four-year universities. The main study found that college students lack confidence in their future success.

In May 2018, Yu ShengNan [21] and others used cluster stratified sampling method to randomly select 640 students from a medical college in Fujian for questionnaire survey. The results showed that medical students' self-confidence scores ranged from 11 to 39, with an average score of (28.73 \pm 4.35$)$. Among them, 10-15 points (inferiority complex) 7 people (1.1\%), 16-25 points (self-perceived normal) 126 people (19.7\%), 26-35 points (confident people), 459 people (71.8\%), 36-40 points (super confident) 43 people (6.7\%). In the same year, Zhang Minting's full-time sample survey of 408 college students in HanShan Normal University showed that college students' self-confidence scores in the individual's birthplace, grade, whether it is a normal student or not, there are significant differences [22].

In 2019, Wang Jian, Xing Lele, and Chen Xiaoqiong selected poor college students from a university in Nanchang to conduct a questionnaire survey. The results showed that the self-confidence of poor college students was at a medium level, and the self-confidence levels in each dimension were interpersonal self-confidence, achievement self-confidence, coping Self-confidence, quality self-confidence and intellectual self-confidence[23]; Xing Lele conducted a survey and analysis of the self-confidence level of 630 impoverished college students in 2019. The results showed that the self-confidence of impoverished college students was at a medium level overall, among which achievement self-confidence and interpersonal self-confidence were at a moderate upper level. Level, intellectual self-confidence, coping self-confidence, and quality self-confidence are at the lower middle level; the self-confidence level of poor college students has significant differences in grades and majors $(\mathrm{P}<0.05)$, but there is no significant difference in other demographic variables $(\mathrm{P}>0.05)[24]$.

\section{Cultivation Strategies to Improve College Students' Self-Confidence}

The self-confidence level of college students is an important indicator of their mental health, which is related to the development and progress of society. In the face of fierce social competition and the high demands and expectations continuously imposed on college students by society, the psychological problems of contemporary college students are becoming increasingly prominent, especially for long-term Incorrect cognition, bad emotions, incorrect comparisons, and the increasingly severe employment situation today, the chance of college students' psychological frustration is increasing, self-confidence is seriously insufficient, and it is easy to form a negative mentality of inferiority complex, and even suicide. Therefore, the lack of self-confidence has a great negative impact on the learning, life, growth and future of college students. Understanding the self-confidence level of college students and formulating corresponding training strategies to improve self-confidence have become an important research topic in the field of education. On the basis of understanding the current state of self-confidence of college students, this study combines the learning and living conditions of current college students and proposes some feasible Strategies to promote college students' self-confidence. 


\subsection{Carry Out Mental Health Courses to Cultivate the Self-Improvement Awareness and Ability of College Students}

Mental health courses are the main front for college students' health education and the main platform for fostering college students' self-confidence. Then, set up a mental health education course for all college students, teach the impact of self-confidence on individuals and self-confidence improvement methods to college students in the course, and can monitor the results of self-training in classroom training, and really promote their promotion of themselves Level of self-confidence. The improvement of the individual's self-confidence level is conducive to the establishment of a good psychological environment for the group of college students, thereby promoting the improvement of the overall self-confidence level of college students.

\subsection{Carry Out Abundant University Activities, and Extend the Goal of Improving the Self-Confidence of College Students into the Activities of College Students}

The study found that taekwondo [25], aerobics [26], volleyball training, music training [27], group psychological counseling, etc. can effectively improve the self-confidence of college students, and college student activities are an important classroom for improving the self-confidence of college students. These activities can be college students' professional courses, elective courses, or even college students' community activities. As long as the goal of self-confidence improvement is penetrated into the activity training, college students can gain self-confidence by participating in these activities and constantly adjusting and growing themselves. Of course, this requires cooperation from the school level, such as the setting of activity goals, the active development of community activities, curriculum design, etc., and the need to participate in the raising of teacher awareness and the goal of students' self-confidence throughout their teaching guidance. For individual college students, the most important thing is conscious self-improvement, and can actively participate in various activities and constantly adjust themselves in the activities.

\subsection{Improve the Reward System and Strengthen the System to Create a Multicultural Atmosphere on Campus}

Confidence comes from a successful experience. Continuous success promotes the improvement of individual self-confidence. Success is very subjective for individuals. For example, the success of a speech is called success, but for those who never dare to speak in front of the public, it is a success to be able to express their views to the audience successfully, and it will encourage Once again, he dared to express himself. Big success requires continuous efforts of individuals, but small success experience can be created by school or society. For example, the honor of the class, the mission of the association, the rewards of the school, etc., we can focus on small things, we can also encourage students to develop themselves, create some successful experience opportunities, improve the reward system and strengthen the system, so that students have more opportunities Experienced success can better enhance their self-confidence level.

\section{References}

1. Che Liping. Research on the concept, psychological mechanism and function of self-confidence [J]. Journal of Southwest Normal University (Humanities and Social Sciences), 2002, 28(02): 86-89.

2. Johnson D \& Fowler J H. The evolution of over confidence. Nature, 2011, 477(7364): 317-320.

3. Che Liping, Huang Xiting. Research on the theoretical construction of self-confidence of young college students. Psychological Science, 2006, 29(3): 563-569.

4. Bi Chongzeng, Huang Xiting. Confidence and Health. Research and Practice of Health Care Medicine, 2008, 5(1): 4-8.

5. Bi Chongzeng, Huang Xiting, Dou Gang. A preliminary study on the classification of young students' self-confidence. 1163-1166.

6. 16 Kernis MH, Grannemann BD \& Mathis L C. Stability of self-esteem as a moderator of the relation be- tween level of self-esteem and depression. Journal of Personality and Social Psychology, 1991, 61(1): 80- 92 
7. Feng Jin. A review of psychological resilience research. Journal of Southwest University (Social Science Edition), 2012, 38(2): 1-7.

8. Beattie S, Hardy L, Savage J, et al. Development and validation of a trait measure of robustness of self-confidence. Psychology of Sport and Exercise, 2011, 12(2): 184-191.

9. Huang Yu, Pan Yun, Huang Yafu. Research on the relationship between self-confidence and achievement motivation of college students in independent colleges. Research and Practice of Healthcare Medicine, 2012, 9(3): 19-21.

10. Zhang Jiyuan, Bi Chongzeng. The relationship between self-confidence and interpersonal distress: the mediating effect of clarity. Journal of Southwest University (Natural Science Edition), 2012, 34 (8): 145-148.

11. Lu, L. In Pursuit of Happiness: The Cultural Psychological Study of SWB[J]. Chinese Journal of Psychological, 2005 (2): 99-112.

12. Lu, L. what is happiness[J]. Journal of Happiness Studies, 2004 (5):269-291.

13. Zhang Jiyuan, Bi Chongzeng. The relationship between self-confidence and interpersonal distress: the mediating effect of clarity [J]. Journal of Southwest University (Natural Science Edition), 2012, 34(08): 145-148.

14. Sun Bin, Ge Cao. Research on the relationship between self-confidence, social support and college students' status-trait anxiety[J]. Journal of Zhoukou Normal University, 2015 (2): 154-156.

15. Wei Yaoyang, Wang Yan. Research on the relationship between social support, self-esteem and social self-confidence of college students[J]. Contemporary Vocational Education, 2018(04): 90-95.

16. Anhui Ming. The related research of college students' self-confidence, self-esteem, self-efficacy and mental health [J] Chinese Journal of Clinical Psychology, 2000 (4): 227-228.

17. Liu Wei, Research on the Effect of Centralized and Closed Group Consultation on Improving Self-confidence of College Students, Chinese Journal of Clinical Psychology. 2009.03:381-382.

18. Zhang Zhijun, Correlation analysis of college students' self-confidence and family upbringing, Journal of Ankang University, 2011(8).

19. Zhu Chuanlin, Qi Zhengyang, Cheng Juan, Li Ping, Li Shuaixia, Wang Wei. Investigation report on the self-confidence level of college students, Social Psychological Science. 2015.05: 58-61.

20. R. Maheswari, K. Maheswari. Research on college students' self-esteem, IOSR Journal of Humanities and Social Sciences. 2016(10): 08-10.

21. Yu Shengnan, Xiao Huixin, Deng Shangqing, Research on the correlation between self-worth and self-confidence of medical students, China Higher Medical Education, 2018(5):27.

22. Zhang Minting, Characteristics and related research of college students' self-confidence and social support, theoretical research, 2018, 03: 36-38.

23. Wang Jian, Xing Lele, Chen Xiaoqiong. Investigation report on the level of self-confidence of poor college students[J]. Journal of Nanchang Teachers College, 2019, 40(03): 102-107.

24. Xing Lele. Investigation and intervention research on the level of self-confidence of poor college students [D]. Nanchang University, 2019.

25. Wang Xurui. Discussion on the influence of aerobics on the self-confidence of college students [J]. Contemporary Sports Science and Technology, 2020,10(09):242-243.]

26. Sun Yue. Research on the influence of taekwondo on college students' self-confidence Taking Nanchang University as an example[J]. Sports, 2019(02):44-45.

27. Yuan Dandan, Liu Zhaoping. Analysis on the countermeasures of music literacy to enhance the self-confidence of vocational college students[J]. Art Works, 2017(18):74-75. 